\section{OBJECTIONS TO HUMORAL PATHOLOGY.}

By R. Stevens, M.R.C.S., Kennington.

In all the objections which have been made to M. Magendie's views about the action of carbonate of soda, certain necessary principles have been lost sight of; moreover, M. Magendie hinself, throughout the whole of his experiments, is liable to the same charge in more important matters still.

When IM. Magendie injects carbonate of soda into the veins of an animal whose solids and fluids are all in the normal condition, and organic lesion is the consequence, he is not on that account justified in inferring that carbonate of soda is an injurious drug; that it should not be used in a state of disease, where the fluids are in an abnormal condition; for this makes all the difference. It being administered as a remedy only where the fluids are in a state of abnormal acidity, which is, according to his own ex periments, as injurious as abnormal alkalinity.

I have had a gentleman under my care for the last four or five years, who has been seen by many of the most eminent physicians and surgeons in London, with the lithic diathesis and deposit in the kidney, caused, as I believe it always is, by abnormal acidity of the stomach, which when taken into the system displaces urea from its chemical associations. He has taken alkalies in large quantities during the whole period, and knows well the necessity of abstaining from all acids; and so long as there is acidity to neutralise it is impossible for the alkalies to be injurious, whilst the acidity, if left alone, would soon prove fatal. I find a very general prejudice to the use, as well as to the abuse, of opium, as well as other remedies; but if a person be labouring under any local pain or inritation. and the doses be well adjusted, it will allay this without producing sleep, or confined bowels, or any other effect which the patient looks upon with prejudice.

Surely M. Magendie would not have us treat all diseases upon chemical principles; for the disease $I$ have brought forward is only one of a class. Are the only data admitted into our reasoning to be those which we acquire by our sensual perception? If so, how limited our powers. But were the courses and distances of the planets ascertained by actual admeasurement, or by intellectual data worked out?

When typhoid exhaustion takes place at the finish of any inflammatory disease, $M$. Magendie would find the blood defibrinised and attenuated: but this is not a cause, but an effect. Would he deny the pre-existence of that which we call inflammatory excitement? For if so, he would from the first treat the disease with such remedies as increase the quantity of fibrine in the blood; in short, by tonics. (Heu! miserabile.)

In the 18th experiment, published in last week's LanceT, p.572, does M. Magendie draw any inference as to the medicinal effect of emetic tartar from the consequences which followed the injection of a drachm of this salt into the veins of a $\operatorname{dog}$ ? When he states that it is much used in pnenmonia with a view to acting on the respiratory organs, and in rheumatism, and that some practitioners give it with quinine in certain intermittent fevers, he has named its empirical uses only; but if he draw the inference from his experiments, that it does not act, in small doses, as a direct sedative to the nervons, or functional power; that it does not allay excited action (cutting it short better and shorter than bloodletting, because there is no detraction of substance, no defibrinisation as he would call it, and consequently, a quick convalescence), we must dispute the point; and when he denies that there is such a thing as we call inflan. mation (for what else should we call it?) and directs his remedial intentions to the effects of inflammation alone, namely, defibrinisation and attenuation of the blood, he publishes dangerous doctrines, and the more so because such a name as his own is attached to them. Moreover, M. Magendie being ignorant of the scientific uses of this medi. cine (for I am justified in saying so), styles it a vaunted drug, and states that after a few weeks' trial of it (in such diseases as he names, I suppose), he ceased to use it altogether.

Also in the 9th experiment, where alum is added to blood, he states that " it is em. ployed under the impression that it acts as a very powerful astringent, yet you see," says he, "that not a irace of coagulum is to be detected here." Does M. Magendie infer from this that alum is not an astringent? and that it should act on the fluids as an absorbent instead of on the tone of the solid vessels as an astringent? He states, for the same reason, that it is possible that sul. phuric acid rather promotes the escape of blood from the vessels. (See LANCET, p. 542.) Does not a pledget of lint dipped in diluted sulphuric acid stop bleeding from the nose? M. Magendie should make his experiments on the solids as well as on the fluids, and not apply facts of one condition to results of another, which he does when he infers that sulphuric acid may increase hæmorrhage. A man of the highest order of intellect may be wrong sometimes. A friend of mine, a most accomplished mathematician, accounted for the buoyancy of steam by supposing it to consist of globules filled with hydrogen. Ignorant of the chemical principle that matter exists either as the solid, fluid, or gas, according to the quantity of caloric combined with it, he sought for a more physical cause. 
Having mentioned the subject of typhoid exhaustion, some instruction can be obtained from Mr. Whitmore Clarke's report of a man who submitted himself to the bite of a rattlesnake for the cure of elephantiasis, which appeared in TuE LANCET for the 15th of December ult.; but the trentment was not well adapted to oppose the effects produced npon the system, which were essentially an extravagant supply of nervous or functional power, causing arterial excitement, and augmentation of the secretions. From whatever cause this may take place, all the nutritious matter contained in the blood is quickly deposited, absorption being as active, with attenuation of the fluids and relaxation of the solids, constituting typhoid exhaustion.

In this man there was a full quick pulse, swelling, redness, numbness, tremor, delirium, copious perspiration and constant excretion of urine, salivation; and after five hours of such action, torpor and great prostration, discharges of sanguinolent fluid from the nose, and bloody urine. After fifteen hours, convulsions and sinking, and death in twenty-four, decomposition taking place immediately, showing how completely the vitality had been exhausted and used up.

Now, the effect of the venom was excitement, and the remedies administered were not sedatives but stimulants; wine and water, rum and water, infusion of guaiaco, with eau de luce. The tartar emetic, judiciously used, would have been the best remedy ; for in this case, as in the early stage of typhus, small-pox, and other specific fevers, we cannot find a direct antidote to the poison causing these diseases, but we can very energetically oppose the effects produced upon the system, and so answer every purpose in a manner wonderful to those not acquainted with this method.

\section{MECHANISM OF RESPIRATION.}

\section{To the Editor of THE LANCET.}

SIR:-As I consider the paper of Mr. Goodman in Tue Lancet of Dec. 29, on the important subject of the heart's action, to be open to some objections, permit me to make the following observations on it, by giving publicity to which you will much oblige, Sir, your obedient servant,

54, Frith-street, Soho, JoHn SNow, M.R.C.S.

Jan. 5, 1839 .

After some preliminary observations, Mr. Goodman, speaking of the thorax, says,"The outer walls, or bony arch, possess such strength of material, and peculiar convex form, that the pressure of the atmosphere, generally understood to be $15 \mathrm{lbs}$. on every square inch of surface, is firmly and perfectly sustained by this mechanism, and the contained viscera are protected from its influence."

Now, the most delicate structures on the earth bear the pressure of the atmosphere without detriment, so long as it is equal in all directions; a distended bladder, and bubbles blown in soap and water, bear it, because it is equal inside and out; but this is not what Mr. G. means with respect to the thorax, for he says, "the contained viscera are protected from its influence," which they could not be unless the pressure were entirely on the ontside. A thorax, 10 inches deep and 30 inches in circumference (not a very large one), has $\mathbf{3 0 0}$ square inches of surface, and would, in this case, have to resist a force of $45001 \mathrm{bs}$, , or more than two tons; and, in addition, the diaphragm and the parts closing the top of the thorax, wonld have to resist half as much; this would require thick walls of cast iron instead of mere flesh and bone. The truth is, that with very slight variations the pres. sure on every part of the thoracic viscera is exactly the same as on the exterior of the chest. The walls of the thorax are moveable and elastic, and are exactly applied to the surface of the lungs in all their changes in size, and the atmosphere that presses on these walls presses them on the lungs; the atmospheric pressure also, on the walls of the abdomen, is communicated by means of the abdominal viscera and diaphragm, withont the slightest diminution to the viscera of the thorax ; and the atmosphere commu. nicating with the interior of the lungs, balances, between the respirations, exactly the pressure outside; it makes no difference that the mouth and nostrils be closed, for the pressure of any given volume of air is precisely the same as that by which it has been compressed. The slight variations of which I have spoken are, that during inspiration the pressure in the interior of the chest is a little less, and during expiration a Jittle more, than on the exterior; that this difference is very minute, $I$ will prove at the end of this paper.

Immediately after the sentence I have quoted, Mr. Goodman continues:-_" Not only does this protecting arch resist the force of external pressure, but it is also capable, to a certain extent, of expanding itself, and producing a partial vacuum within its parietes." The latter part of this sentence is not at variance with fact. Mr.G. continues, - "The diaphragm, or floor of this cavity, is also able to resist the power of atmospheric pressure, although of muscular construction." I need not comment on this, after what I have said above.

The experiment of removing the heart through an opening in the diaphragm, and then inflating the lungs, does not prore that the pericardium is capable of resisting any 